\title{
CHARACTERIZATION OF PROCESSES INVOLVED IN THE RESET OF A SUBTIDAL BAR
}

\author{
Brice Blossier ${ }^{1}$ Christophe Brière ${ }^{1}$ J.A. Roelvink ${ }^{1}$ D.J.R. Walstra ${ }^{1}$
}

\begin{abstract}
Sand beach profiles can exhibit nearshore sandbars with complex 3D patterns. Under energetic conditions, these patterns disappear and the bars get to a certain extent alongshore uniform. This phenomenon is called a reset. The existing literature mainly concerns the development of the bar patterns (3D) or the cross-shore migration of sandbars (2D). Studies on reset-events from a three dimensional point of view are limited but can be found for instance in Reniers et al. (2004) and Smit (2010). This paper describes an analysis that is aimed at determining the relevant processes involved in the reset of three dimensional subtidal bars and at describing the relative influence of each of these processes. To perform this study, data collected during the ECORS campaign at Le Truc Vert (France) in 2008 are analyzed. In addition, a numerical approach is performed using a research Delft3D model forced by the Xbeach wave generator to investigate the processes involved in a reset-event. The effects of the hydrodynamic external conditions on the flow patterns in the surfzone are investigated. Then the reset is studied in details in order to understand the role of the different processes taken into account by the numerical model. The incident wave energy controls the intensity of the reset. The bar cross-shore migration is controlled by the wave breaking process. The wave breaking position and the dissipation rate of the roller energy controls the generation of Shoreward Propagating Accretionary Waves (SPAW). The straightening of the subtidal bar occurs when the conditions induce a significant longshore current in the surfzone.
\end{abstract}

Keywords: nearshore sandbars; energetic conditions; reset; process-based modeling; bar migration; Truc Vert

\section{INTRODUCTION}

Nearshore sandbars are commonly observed in nature and remarkably exhibit similar patterns everywhere. Bars may be multiple, alongshore uniform or present complex 3D patterns. These patterns may be regular, showing spatial periodicity and multiple bars may be coupled (Castelle et al., 2010b). This is for instance the case at Palm Beach in New South Wales, Australia (Holman et al., 2006), at Duck, North Carolina, USA (Falqués et al., 2008) and Le Truc Vert, France (Castelle et al., 2007).

Nearshore sandbar dynamics is studied mainly because bars play a major role in influencing strongly the surfzone circulations and the transport of sediments; as well they are directly linked to the occurrence of rip currents. The global understanding of bar morphodynamics including the bar response to energetic wave conditions would enable to gain insight into the evolution of the rips in time and space. Moreover, a better assessment of the hydro-sedimentary processes would be extremely profitable for the validation and the evaluation of multiple coastal projects including especially beach nourishments. The large sand amount contained in nearshore bars and their location at the limit of the surfzone give them a significant role regarding the surfzone sediment transfers.

According to the literature, the sandbars complex shapes are the result of partly forced and partly self-organized complex behaviors. The self-organization is a feedback mechanism where the bathymetry is acting on itself thanks to its influence on the surfzone hydrodynamics. This implies consequently specific patterns of sediment transports tending to keep in place bars and rip channels. Numerous studies have been conducted on the bars self-organized behavior (for instance in Smit, 2010; Garnier et al., 2008; Reniers et al., 2004; Droenen and Deigaard, 2007). They are often limited to calm weather conditions and focus in general on the generation and activation of rips. But the sandbars morphodynamics is also depending on the beach characteristics and environment. This forced behavior enabled the elaboration of successive classifications of so-called beach states as a function of the incident hydrodynamic conditions. The first classification has been proposed in Wright and Short (1984), who described six states from the reflective to the dissipative beach. Later, Lippmann and Holman (1990) added two extra states accounting for the structure and the regularity of nearshore sandbars. Later, Masselink and Short (1993) introduced the influence of the tidal range. In those classifications, extreme energetic conditions lead to a large energy dissipation in the surfzone, inducing the formation of one or multiple sandbars parallel to the shore, straightened in the alongshore direction. The forced straightening of a bar under energetic hydrodynamic conditions is called a reset-event.

${ }^{1}$ Deltares - WL | Delft Hydraulics, P.O. Box 177, 2600 MH Delft, The Netherlands. 
In 2008, one of the objectives of the ECORS campaign (Sénéchal and Ardhuin, 2008) was to gather data related to the hydrodynamics and morphodynamics of Le Truc Vert beach (France) in order to improve the understanding of nearshore sandbars behavior. During the campaign, a decennial storm with offshore significant wave heights reaching $8 \mathrm{~m}$ at $50 \mathrm{~m}$ depth has been responsible for the reset of the subtidal bar of this double barred beach. The ECORS dataset is therefore a significant input regarding the existing measurements performed above a barred beach as the reset-event has been remarkably recorded.

There has been little research on the reset of sandbars in the literature and the knowledge about it is mainly descriptive (Howa, 2003). Using the data collected during ECORS, the present study is aimed at improving this knowledge by determining the relevant processes involved in the reset of a subtidal bar.

\section{DATA AND METHODOLOGY}

\section{Le Truc Vert ECORS field experiment}

The site of Le Truc Vert is located on the Atlantic Coast of France along the Aquitanian region, 10 $\mathrm{km}$ northward of the Arcachon lagoon inlet and $90 \mathrm{~km}$ southward of the Gironde Estuary (Castelle et al., 2007). The Aquitanian coast is relatively straight and undisturbed, directly facing the Atlantic Ocean. This large exposure results in a characteristic wave climate, strongly seasonally varying. Most of the incident waves are long-time traveling swell waves from the W-NW direction, but during the winter, relatively strong storms occur and modify the morphology of the beach. The average incidence of the waves creates a longshore current driving the sand southward and inducing an erosion of the coast.

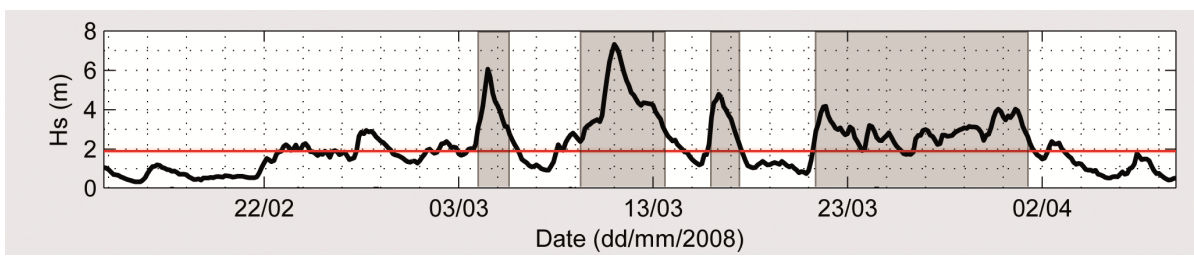

Figure 1. Significant wave height measured during the ECORS campaign at $20 \mathrm{~m}$ depth.

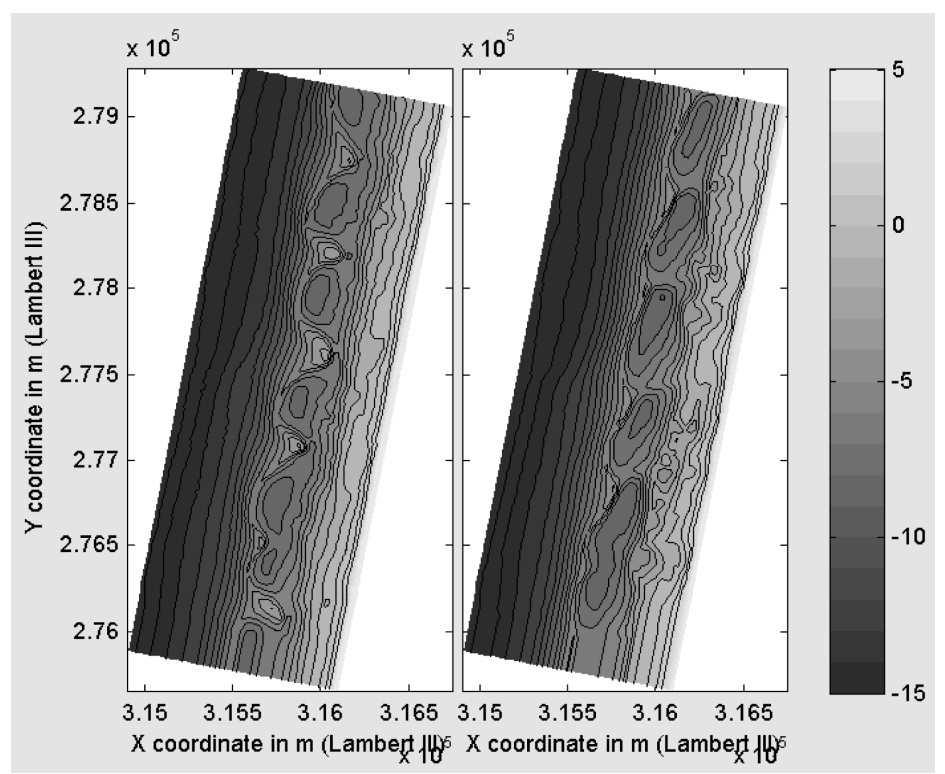

Figure 2. Bathymetries measured the $14^{\text {th }}$ of February, 2008 (left) and the $4^{\text {th }}$ of April, 2008 (right) during the ECORS campaign. Contour lines give the bed level from $-16 \mathrm{~m}$ to $+2 \mathrm{~m}$ by steps of $1 \mathrm{~m}$.

The beach of Le Truc Vert is a double barred beach. A deep subtidal outer bar develops a few hundred meters from the coast meanwhile an inner bar can be observed in the intertidal zone. These 
bars, most of the time, form some crescentic patterns and migrate in the alongshore and cross-shore directions, depending on the wave climate. During strong winter storms, a reset of the bars can be observed as it happened in 2008 during the ECORS campaign.

The significant wave heights $(H s)$ measured at Le Truc Vert during ECORS (see Fig. 1) show that four main storms (represented in gray) occurred. The second storm appeared to be a decennial storm with $H s$ reaching $7.4 \mathrm{~m}$. Almar et al., 2010 shows that the reset of the subtidal bar occurred during this storm thanks to video imagery.

Two bathymetries have been measured by the French Navy (SHOM) the $14^{\text {th }}$ of February and the $4^{\text {th }}$ of April (see Fig. 2). On the initial bathymetry (left) the crescentic shapes of the subtidal bar are clearly developed meanwhile the bar has significantly straightened at the end of the campaign (right).

Seven instruments deployed by the Naval Postgraduate School (NPS, USA) and the University of Miami (USA) have measured the water pressure and the velocities with a $5 \mathrm{~Hz}$ resolution during the entire campaign, providing data during the decennial storm. These sensors were located around the low water line as presented in Fig. 3 and are numbered from 2 to 8 from north to south.

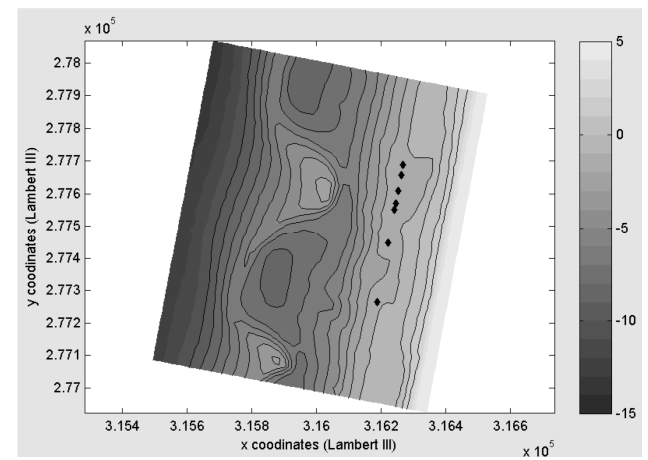

Figure 3. Locations (black dots) of seven sensors deployed by the University of Miami during the ECORS campaign plotted on the initial bathymetry. These sensors recorded the velocities and the water pressure with a $5 \mathrm{~Hz}$ resolution. Contour lines give the bed level from $-10 \mathrm{~m}$ to $+2 \mathrm{~m}$ by steps of $1 \mathrm{~m}$.

\section{Methodology}

Performing reliable numerous measurements during the complete duration of an energetic event is very complex. Therefore, a process-based numerical modeling approach is chosen here in order to study the processes that are relevant in a reset-event. The case of Le Truc Vert is used as a support to set a reference simulation as data are available to first calibrate and then run the model in the real conditions of a reset.

In order to limit the computation time, one external condition is applied per simulation. Therefore a data analysis is initially performed in order to determine the favorable external conditions inducing the reset during ECORS. Following Russell and Huntley (1999), the velocity skewness has been studied similarly to Masselink et al. (2008) using the measurements of the seven sensors deployed by the University of Miami (see Fig. 3). The skewness of the velocity signals enables to characterize the sediment transport at the location of the sensors as the cube of the flow velocities can be considered as being representative of the sediment fluxes. First the signals have been filtered in order to separate their different components. The cross-shore velocity $u$ is thus the sum of its time-averaged value $u_{\text {mean }}$, the low frequency components $u_{L}$ (below $0.04 \mathrm{~Hz}$ ) corresponding to the infragravity wave-induced currents and the high frequency components $u_{S}$ (above $0.04 \mathrm{~Hz}$ ) corresponding to the swell and short waveinduced currents. The same is applied to the longshore velocity $v$. Time-averaging the cube of the decomposed velocities $\left.\left(<\left(u_{\text {mean }}+u_{L}+u_{S}\right)^{3}\right\rangle\right)$ leads to ten velocity skewness terms for the cross-shore velocity as well as for the longshore velocity.

The model used in the present work is a research version combining Delft3D (Lesser et al., 2004) and XBeach (Roelvink et al., 2009). Delft3D is used for the simulation of the flow and the morphodynamics. The flow is computed using the flood scheme of Delft3D supporting the flooding and drying of computational cells (Stelling and Duinmeijer, 2003). The sediment transport is computed according to the formulation of Van Rijn, 2007 accounting for the current-induced and the short waveinduced bed and suspended transport. Xbeach is used to generate the wave climate, enabling the 
propagation of wave groups in the model and thus the generation of long waves in the flow modeled in Delft3D.

The approach followed in this study consists in performing a sensitivity analysis on the nearshore processes able to play a role in the reset-event. First, a reference simulation is set up using the favorable conditions resulting from the velocity skewness analysis. Then, in order to understand the flow patterns above the bar, the hydrodynamics is first analyzed and its sensitivity to the description of different processes including the wave climate forcing and the wave breaking is assessed. Finally, the morphodynamics is studied. The influence of the external hydrodynamic forcing in the reset is evaluated as well as the role of the wave breaking, the wave groups, the wave-current interaction and the bed forms generation (see Van Rijn, 2007).

\section{RESULTS}

\section{Data analysis results}

The velocity skewness at the seven sensors locations is evaluated per 20 minutes sections of the cross-shore and longshore velocity signals. In both directions, three skewness terms over the ten are largely dominating the others. Only these three terms are presented in the present paper. For the crossshore velocity:

- $u_{\text {mean }}{ }^{3}$ representing the sediments stirred and advected by the mean current.

- $3 u_{\text {mean }}<u_{S}{ }^{2}>$ representing the sediment stirred by the high frequency oscillations and advected by the mean current.

- $3 u_{\text {mean }}<u_{L}^{2}>$ representing the sediment stirred by the low frequency oscillations and advected by the mean current.

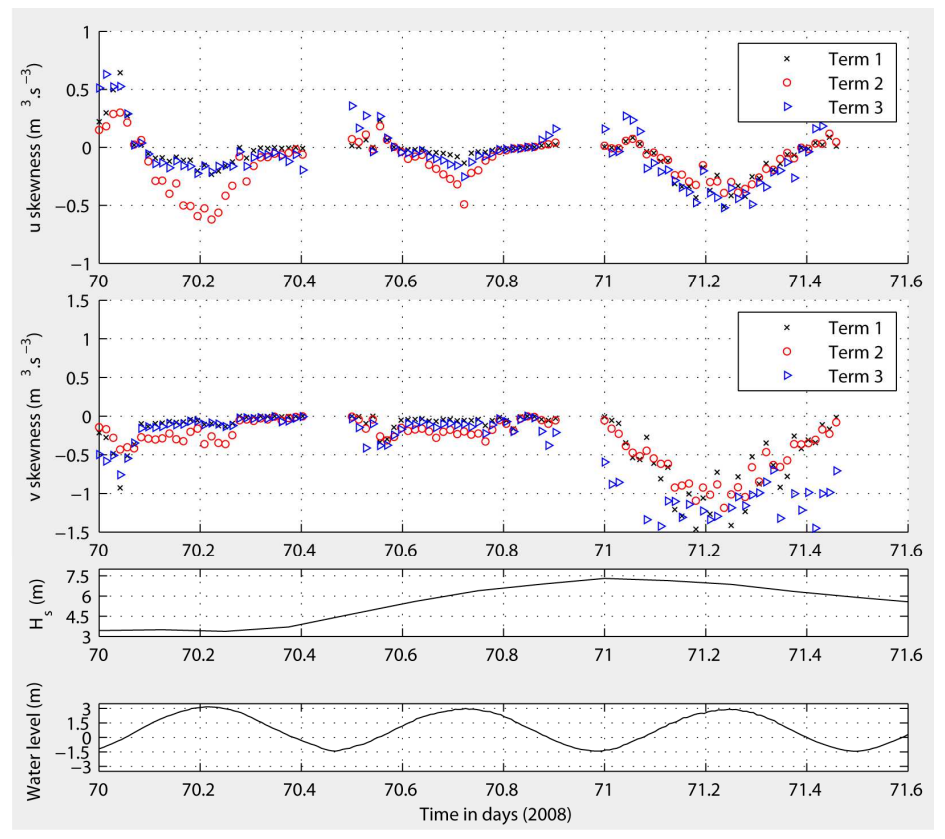

Figure 4. From top to bottom, cross-shore skewness terms, longshore skewness terms, significant wave height and water level measured during the decennial storm. The wave angle of incidence (not plotted here) is almost constant during the storm, with a value of $10^{\circ}$ northward compare to the normal of the beach. $u$ is positive shoreward and $v$ is positive northward.

Because the stirring of sediments is induced by the cross-shore and longshore velocity components, those terms are recomputed with both contributions. For the cross-shore velocity skewness terms:

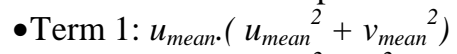

- Term 2: $3 u_{\text {mean }}\left\langle u_{S}^{2}+v_{S}^{2}\right\rangle$

- Term 3: $\left.3 u_{\text {mean }}<u_{L}^{2}+v_{L}^{2}\right\rangle$

The results are equivalent for most sensors and are given in Fig. 4 for sensor number 5 (the cross-shore velocities are positive shoreward and the longshore velocities are positive northward). At very low tide, 
there is no data since the sensors are not in the water anymore. During the reset-event, the subtidal bar is migrating in the offshore direction and the bar horns are migrating southward. Therefore, favorable conditions for the reset should correspond to negative $u$ and $v$ skewness values.

The data shows that in the cross-shore direction, the skewness is negative during the high tide. At low tide, the transport is dominated by the low frequency components and is directed shoreward, reflecting the domination of the infragravity waves at the shoreline. In the longshore direction, the transport is always orientated southward (negative values) due to a nearly constant wave angle of incidence $\theta$ (around $10^{\circ}$ northward compare to the normal of the beach) and becomes more important with higher water levels. During the high tide, the contribution of the low frequency components increases during the storm, meaning that taking them into account in the numerical modeling is relevant.

The conditions during the successive high tides at day 70.7 and 71.2 are very similar in terms of significant wave heights (respectively 6 and $7 \mathrm{~m}$ ) and water levels $(3 \mathrm{~m})$. However, the observed skewness increases significantly, especially in the longshore direction. The present study assumes that this can be interpreted as the effect of the reset of the subtidal bar. Thus the parameters retained for the external conditions of the numerical morphodynamic simulation are the conditions experienced at Le Truc Vert during the high tide prior to day 71.

\section{Hydrodynamic study results}

Calibration. The Delft3D with Xbeach model is first calibrated using data collected in the intertidal area under calm conditions. These measurements have been performed at the end of the campaign by the University of Bordeaux I. The model outputs are compared to 10 minutes-averaged signals of the significant wave height, the cross-shore and the longshore velocities at three different locations in the intertidal area. A fair agreement is reached. The modeled amplitudes of the velocities agree well with the data. The direction can slightly differ but this can be related to the fact that the resolution of the computational grid nearshore $(15 \mathrm{~m})$ is not set for studying accurately the intertidal area. Then the model is calibrated using the data collected by the University of Miami during the storm for one specific energetic condition. The calibration is performed with the bathymetry of the ${ }^{14 t h}$ of February and is qualitative since the exact bathymetry at this time is not known. The model reproduces well the order of magnitude of the significant wave height, the cross-shore and longshore velocities and slightly underestimates the amplitude of the long waves but still reaches around $80 \%$ of the measured values. Amongst the calibration factors, the modeled hydrodynamics are mainly sensitive to the wave bottom friction dissipation parameter $f_{w}$ and the wave breaking parameter $\gamma$. Remarkably, both calibrations led to the use of the same values for $f_{w}(0.15)$ and $\gamma(0.4)$, giving thus some reliability to the model simulations.

Hydrodynamic patterns. The model is then used to describe the hydrodynamics occurring above the subtidal bar during energetic external conditions. Therefore it has been first forced with representative ECORS energetic conditions corresponding to the following parameters:

$\bullet \mathrm{Hs}=6 \mathrm{~m}$.

$\bullet \theta=10^{\circ}$ northward compare to the normal of the beach.

-Directional spreading $=30^{\circ}$.

-Peak wave period $=16.7 \mathrm{~s}$.

-Water level $=0 \mathrm{~m}$.

The forces and the depth-averaged velocities simulated in the model have been averaged over one hour once the equilibrium state has been reached. The results are presented in Fig. 5. The graph on the right shows the resultant forces applied on the flow (black arrows) and the induced current patterns (white arrows). On the left the pressure and the wave induced forces are displayed separately. The water level in gray explains the pressure forces. Two areas of set-up are observed. The first areas are located on the inner beach at the subtidal bar bays locations. This set-up generates strong southward and weak northward currents that can be observed in the right graph. The second areas are located in the trough between the bar horns and the inner beach. The consequences of this set-up are northwest-directed forces at the north of the bar horns and southwest-directed at the south. These southwest forces induce strong longshore currents occurring at the south of the bar horns. The northwest-directed forces participate in a resultant forcing pattern inducing circular motions north of the bar horns. 


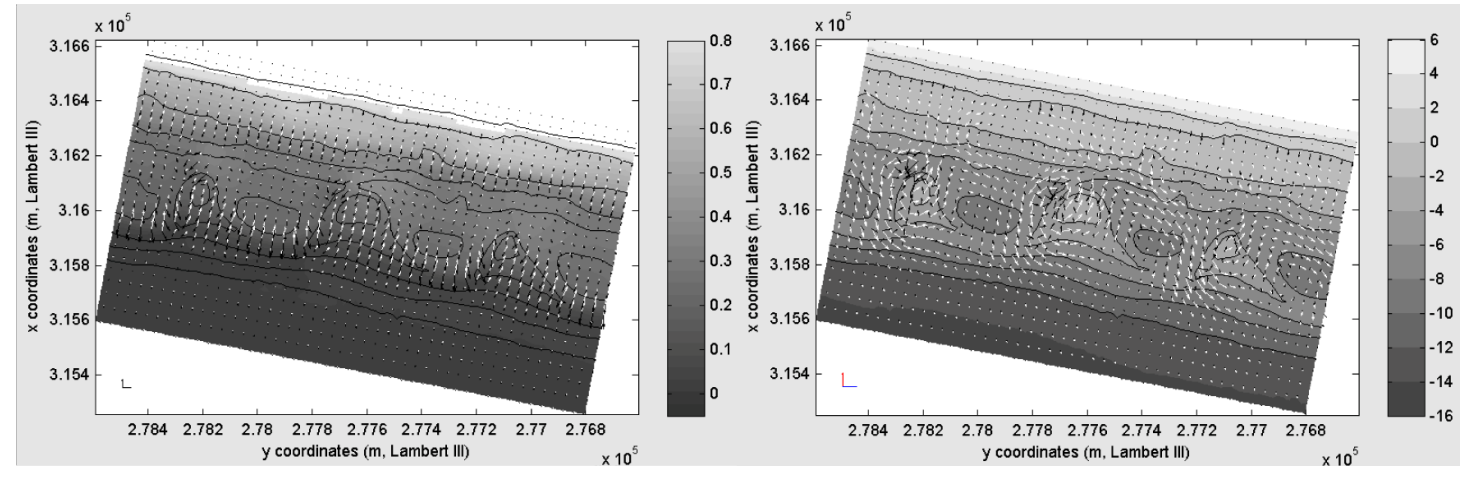

Figure 5. Left: pressure (black arrows) and wave breaking (white arrows) induced forces averaged over one hour after reaching the equilibrium state. The gray scale gives the averaged water level. The bottom left arrows represent $0.3 \mathrm{~N} / \mathrm{m}^{2}$ forces.

Right: velocities (white arrows) and resultant forces (pressure + wave induced forces in black arrows) on the initial bathymetry (gray scale). The bottom left arrows represents $1 \mathrm{~m} / \mathrm{s}$ and $0.5 \mathrm{~N} / \mathrm{m}^{2}$. On both graphs, the contour lines give the bed levels from $-12 \mathrm{~m}$ to $+2 \mathrm{~m}$ every $2 \mathrm{~m}$.

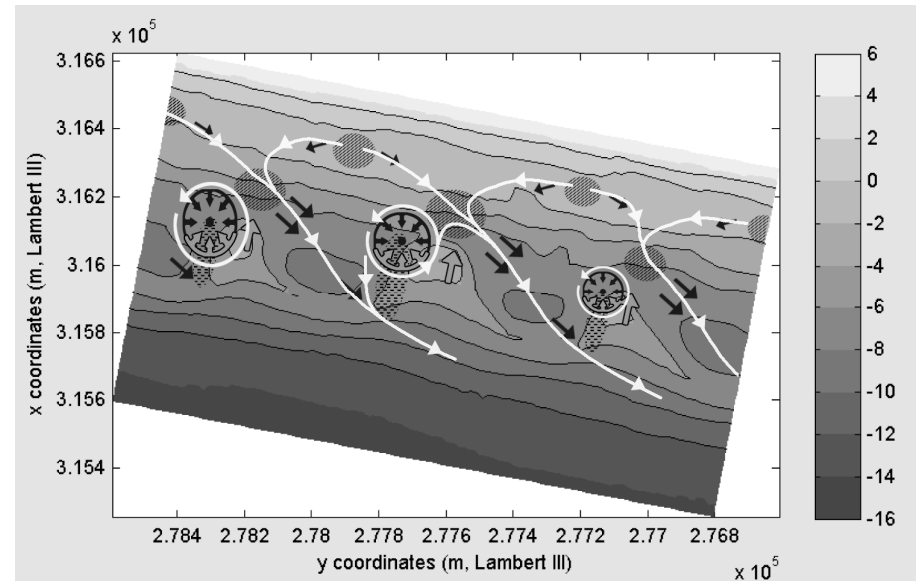

Figure 6. Schematic representation of the main circulations (white arrows) and main forces (black arrows: pressure forces; gray arrows: wave induced forces). The oblique hatching stands for the set-up areas and the horizontal one for the set-down. The gray scale represents the bathymetry and the contour lines give the bed levels from $-12 m$ to $+2 m$ every $2 m$.

A schematic graph of the resultant forcing patterns and the consequent flow circulations is proposed in Fig. 6. Due to the wave angle of incidence, shoaling occurs at the northwest part of the bar horns and induces a set-down (horizontal hatching) explaining the orientation of the pressure forces towards this area. Offshore of the subtidal bar, the wave-induced forces caused by the wave breaking on the horns are orientated shoreward. To summarize, the combination of set-up induced forces (in the obliquely hatched areas shoreward of the horns), set-down induced forces (in the horizontally hatched areas) and wave induced forces (offshore of the horns) leads to a forcing patterns similar to a central force induced forcing pattern. Therefore, circular flow patterns are observed at the north of each bar horn.

Because these circular patterns result from an interaction between the wave-induced forces and the pressure forces, they are strongly influenced by the bathymetry. Therefore, the bar horn located at $y=$ $277100 \mathrm{~m}$ is not extended enough to create a strong set-up in the trough. As a consequence the circular flow pattern is very weak compare to the one occurring above the horn located at $y=277600 \mathrm{~m}$. These circulations depend thus strongly on the wave climate and the water depth above the bar horns.

Hydrodynamic sensitivity analysis. The sensitivity of the hydrodynamics is first evaluated regarding the external hydrodynamic conditions. The time and depth-averaged velocity patterns at the equilibrium state have been compared to those obtained with the reference simulation described in the previous section. The results for offshore significant wave heights of $4 \mathrm{~m}$ and $8 \mathrm{~m}$ at $20 \mathrm{~m}$ depth do not show a significant difference with the reference simulation. The amplitude of the computed velocities 
increases but the circular flow patterns on the bar horns persist.

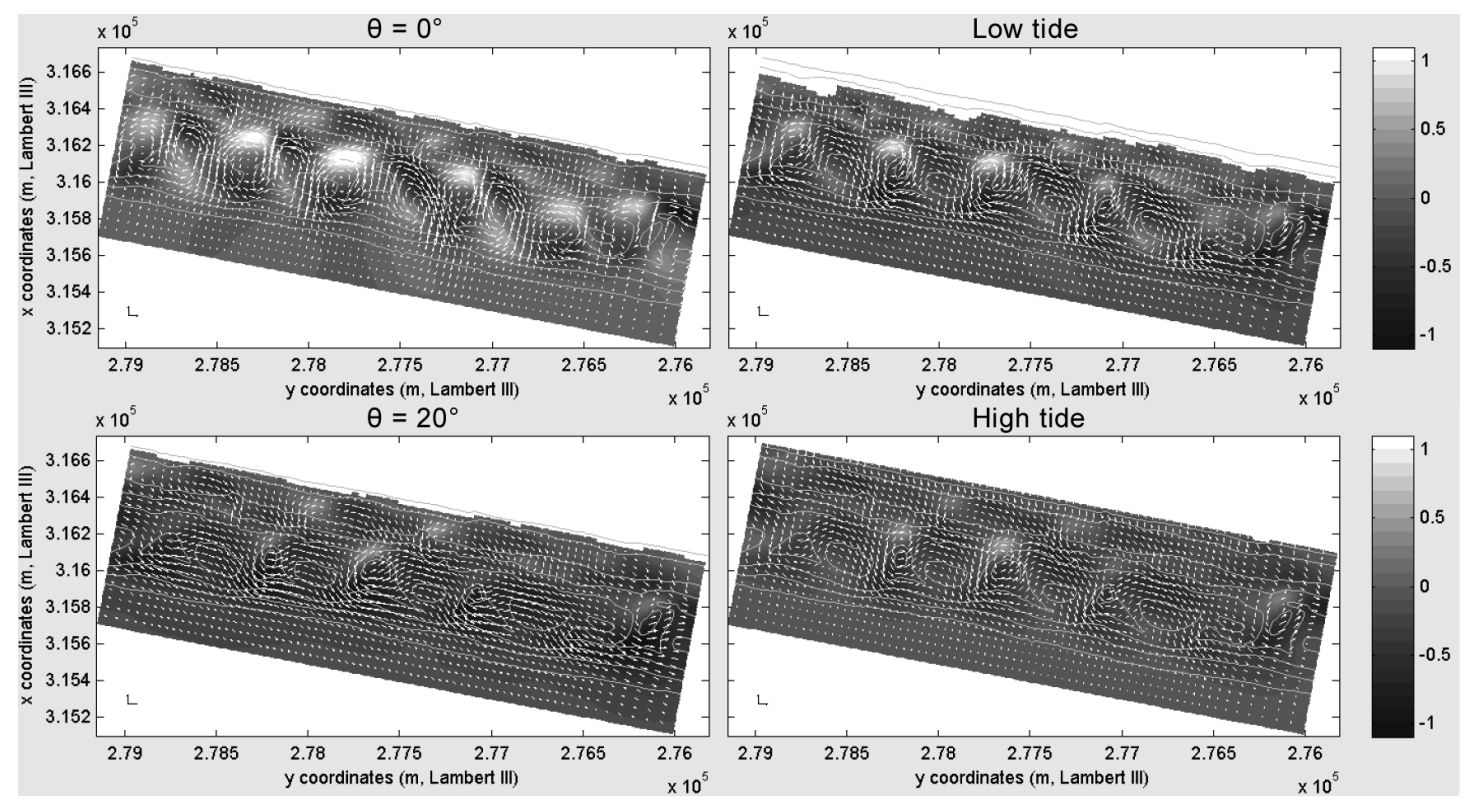

Figure 7. Time-averaged velocities (white arrows) and longshore velocity components (gray scale) for $\theta=0^{\circ}$ (top left), $\theta=20^{\circ}$ (bottom left), low tide water level (top right) and high tide water level (bottom right). Large wave angles of incidence and high water levels increase the southward longshore current intensity. Small angles and low water levels increase the influence of the bathymetry on the flow. Bottom left arrows represents $1 \mathrm{~m} / \mathrm{s}$.

On the contrary, the influence of the water level and the wave angle of incidence is significant (see Fig. 7). A normal angle of incidence results in symmetrical circular flow patterns on each side of the bar horns. Low water levels also tend to increase the intensity of the circular patterns. On the contrary, large angles of incidence and high water levels enable the appearance of a strong southward longshore current and weaken the circular patterns.

The sensitivity of the hydrodynamics is then evaluated regarding the parameters describing the wave breaking process in the model. The breaking parameter $\gamma$ plays the major role. Increasing its value lets the waves breaking further onshore and thus lets more wave energy propagating in the shallow areas. Consequently larger dissipation rates are observed in the surfzone and the currents are more intense. The effect is similar to an increase the wave height. The roller energy dissipation parameter $\beta$ is playing a role in the location of the flow patterns. A larger value induces a shift of the averaged velocity patterns offshore since the roller energy dissipates faster. The breaker delay FacBkd is a parameter enabling to delay the wave breaking by using a triangular average of the water depth in the direction opposite to the wave propagation (thus along the bar slope, the depth considered for the wave breaking is larger than the real depth). Its effect on the flow is similar to the effect of $\gamma$.

\section{Morphodynamic study results}

Reference simulation. According to the data analysis, the reference simulation is set with the external conditions observed during the high tide prior to day 71 :

$\bullet H s=6.7 \mathrm{~m}$.

- $\theta=10^{\circ}$ northward compare to the normal of the beach.

- Directional spreading $=30^{\circ}$.

-Peak wave period $=16.7 \mathrm{~s}$.

- Water level $=2.9 \mathrm{~m}$.

The model settings used in the morphodynamic simulations are very close to those used for the hydrodynamic study. Nevertheless, a few modifications have been made in order to observe a reset. The wave-current interaction is not taken into account due to the fact that it is significantly limiting the reset in the simulations. However its influence is evaluated later. In addition, the viscosity of the flow and the sediment diffusivity are defined using constant values. Whereas the use of the turbulent models 
provides a description of the flow fairly agreeing with the measurements during the calibration, these models failed in the reproduction of a reset-event. For this reason, constant values have been used instead of computing them through $K-L$ or $K-\varepsilon$ models. A value of $0.1 \mathrm{~m}^{2} / \mathrm{s}$ has been chosen for the vertical viscosity in agreement with the bottom values given by the $K-\varepsilon$ model in the hydrodynamic simulations. Regarding the horizontal viscosity and sediment diffusivity, a value of $10 \mathrm{~m}^{2} / \mathrm{s}$ has been used. Even if this value is large, its use led to a significant reset of the bar. Smaller values have been evaluated afterwards and led to a significant reset as well. Nevertheless the value of $10 \mathrm{~m}^{2} / \mathrm{s}$ has been conserved in the reference simulation due to the heaviness of the numerous simulations and considering that the impact on the main conclusions of this study would be limited. The use of constant viscosities and diffusivities is a limitation regarding the accurate description of the nearshore processes. Indeed this choice leads to a simplified description of the flow velocity in the water column (parabolic profile) and does not enable to take into account the varying sediment stirring induced by the varying turbulence intensity. However, the influence of the external hydrodynamic conditions and of the processes not directly linked with the description of the turbulence can still be assessed.

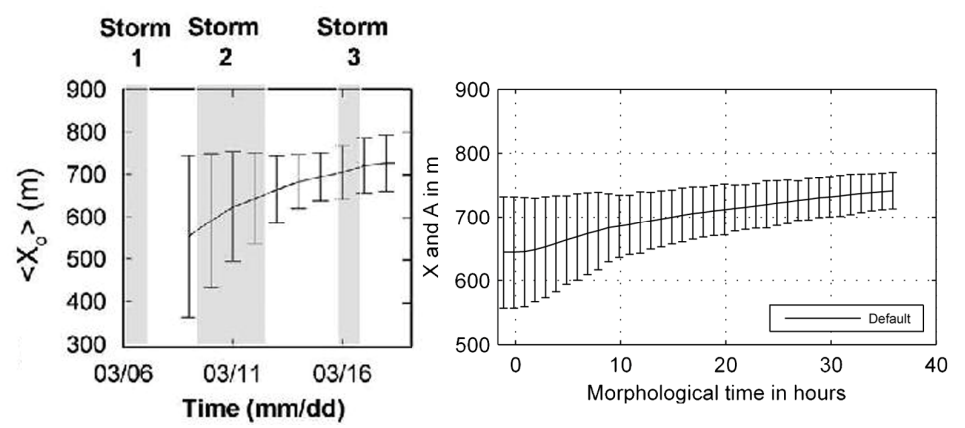

Figure 8. Alongshore averaged cross-shore position $X$ (line) and alongshore averaged amplitude of the crescents $A$ (error bars) of the subtidal bar as found in Almar et al., 2010 (left) and in the reference simulation (right). Initial values are different since the alongshore segments of the bar used for computing $X$ and $A$ are not identical in both studies. The evolution of the subtidal bar in the simulation qualitatively agrees with the evolution measured during the decennial storm (storm2). However it occurs faster in the simulation.

In order to characterize the reset-events in the different simulations and to compare them with the reset-event of the reference simulation and of the observations, the alongshore averaged cross-shore position $X$ of the subtidal bar and the alongshore averaged amplitude of the bar crescents $A$ (half the difference between the alongshore-averaged cross-shore position of the horns and the alongshoreaveraged cross-shore position of the bays) is considered similarly to Almar et al., 2010. The reset obtained in the reference simulation is compared to the measurements in Fig. 8.

The evolution of the subtidal bar during the reset is qualitatively similar to the observations of Almar. During the simulation, after 36 hours, X increased by $100 \mathrm{~m}$ and A has decreased by $66 \%$. During the decennial storm, much more time has been necessary to reach the same values (around three days, i.e. 72 hours) but this can be explained by the fact that the significant wave height did not stay above $6.7 \mathrm{~m}$ more than 15 hours (see Fig. 1).

The evolution of the morphology in the simulation is presented in Fig. 9. The offshore migration of the bar as well as its straightening can be clearly observed. There is an excessive smoothing of the small scale structures in the model due to the high viscosity employed in the simulation. Therefore improvements have to be done on the turbulence parameterization as described previously in this section. However the bar is absolutely stable at the end of the simulation as shown in Fig 10. The alongshore averaged cross-shore distance and the alongshore averaged level difference between the subtidal bar crest and its trough (shoreward) reach constant values after 30 hours of simulation (see respectively $\alpha_{h}$ and $\alpha_{v}$ in Fig.10). $\alpha_{v}$ decreases significantly due to the smoothing of the bar from $1.2 \mathrm{~m}$ to $0.2 \mathrm{~m}$. The final value is small but does not take into account the average slope of the beach. With an actual slope of about 0.013 and a final average cross-shore crest-trough distance $\alpha_{h}$ of $200 \mathrm{~m}$, the bar is observed for $\alpha_{v}>-200 \times 0.013=-2.6 \mathrm{~m}$. A value of $0.2 \mathrm{~m}$ shows therefore a good conservation of the bar profile. 


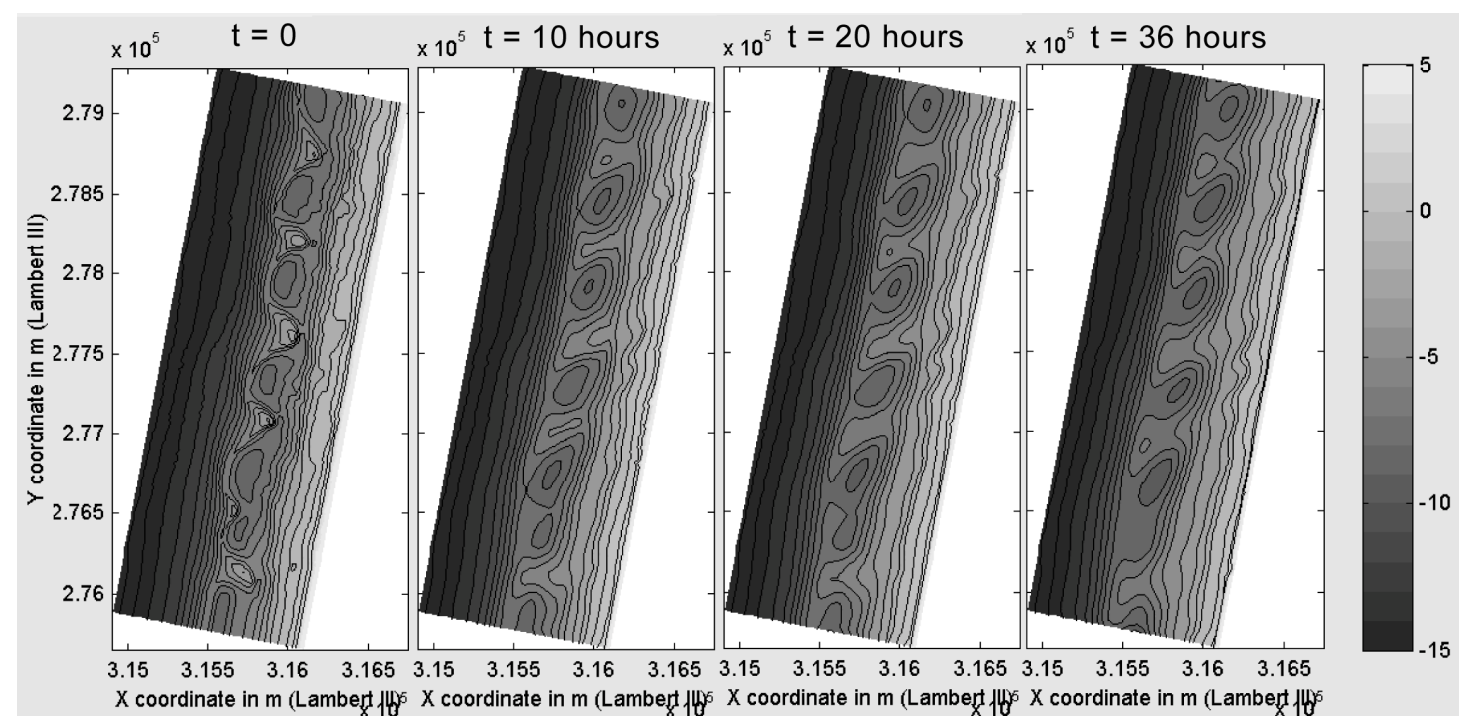

Figure 9. Four successive bathymetries $(t=0, t=10 h, t=20 h$ and $t=36 h)$ in the reference simulation. The offshore migration of the bar can clearly be observed as well as its straightening and the welding of some of its horns extremities (generation of SPAWs).

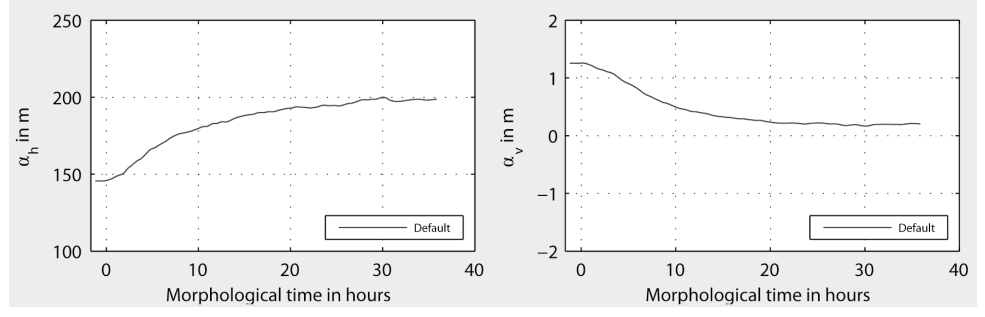

Figure 10. Alongshore averaged cross-shore distance and alongshore averaged vertical difference between the subtidal bar crest and its trough. After 30 hours, $\alpha_{h}$ and $\alpha_{v}$ have reached constant values, meaning that the subtidal bar reached a stable state after the reset.

Qualitatively, the evolution in the model agrees thus with the observations and the reference simulation is used in order to perform a sensitivity analysis on the external conditions and the parameters defining the nearshore processes.

Morphodynamic sensitivity to the external conditions. Significant differences have been observed regarding the hydrodynamics above the subtidal bar for different external conditions. This is observed as well in the behavior of the subtidal bar during the simulated reset-event as shown in Fig. 11. For lower energetic conditions $(\mathrm{Hs}=4 \mathrm{~m})$, the subtidal bar hardly resets. After 36 hours, the bar slightly migrates offshore (about $20 \mathrm{~m}$ ) and the averaged crescents amplitude $A$ decreased by $29 \%$. With more energetic conditions $(\mathrm{Hs}=8 \mathrm{~m})$, the bar migrates further offshore $(135 \mathrm{~m}$ instead of $100 \mathrm{~m}$ in the reference simulation). The averaged crescents amplitude varies similarly to the reference simulation with a decreasing of $66 \%$.

Varying the wave angle of incidence does not influence the cross-shore migration of the bar as presented in Fig. 11. However, it deeply controls the evolution of the alongshore variability of the bar. When the waves are normal to the beach, the crescents are conserved during the migration of the subtidal bar and $A$ is almost constant. On the other hand, with an angle of $20^{\circ}$ instead of $10^{\circ}$ in the reference simulation, the variability decreases by $80 \%$ instead of $66 \%$.

The last graphs at the bottom in Fig. 11 shows the evolution of $X$ and $A$ for different water levels and for one simulation performed with three successive tidal cycle starting at the mean sea level during the ebb tide. First of all, the cross-shore bar migration directly depends on the water level with a larger migration observed for lower water levels. In the simulation performed with three tidal cycles, an intermediate migration is observed and results from successive migrations occurring during the low tide periods. The amplitude of the bar crescents does not decrease in the simulation performed with the low tide water level, it even increases slightly. 

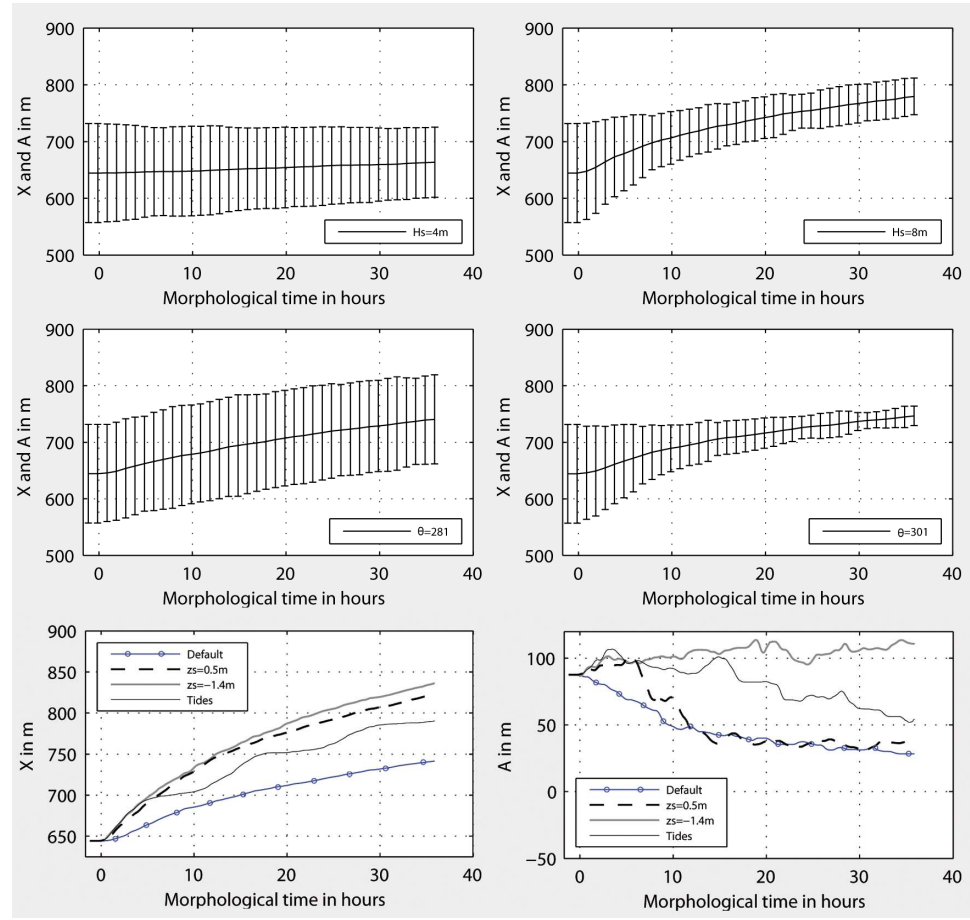

Figure 11. Alongshore averaged cross-shore position $X$ (line) and alongshore averaged amplitude of the crescents $A$ (error bars) of the subtidal bar for different simulations: $\mathrm{Hs}=\mathbf{4} \mathrm{m}$ (top left), $\mathrm{Hs}=\mathbf{8} \mathrm{m}$ (top right), $\theta=0^{\circ}$ (middle left), $\theta=20^{\circ}$ (middle right). At the bottom, $X$ (left) and A (right) are plotted separately for different water levels (low tide (thick gray line), mean sea level (dotted line), high tide (reference simulation, line with circle markers) and three tidal cycles (thin black line)).

In the simulation performed with the mean sea level, the variability starts to grow during five hours and then decreases quickly to values similar to the reference simulation. This can be explained by the evolution of the subtidal bar during the simulation (see Fig. 9). Indeed at the beginning of the reset, the onshore part of the bar horns can move shoreward depending on the external conditions and weld on the upper beach. This phenomenon is particularly clear for the largest horn $(\mathrm{y}=277600 \mathrm{~m})$ and corresponds well to the observations. Indeed, Almar et al. 2010 shows the appearance of a so-called Shoreward Propagating Accretionary Wave (SPAW) at the location of the large horn during the storm. The initial increasing of A at low tide is due to a large initial welding of the bar horns. After several hours, the SPAWs separate and the remaining part of the subtidal bar migrates offshore and straightens.

Morphodynamic sensitivity to the nearshore processes parameterization. The sensitivity of the simulation to the processes parameterization enables to understand the reset mechanisms in the model. All the simulations are performed with the exact same boundary conditions in order to enable the comparison. Only the most relevant effects are presented in this paper.

First the influence of the wave breaking process on the subtidal bar reset is assessed through the influence of the wave breaking parameter $\gamma$, the roller energy dissipation rate $\beta$ and the breaker delay $F a c B k d$. Using a larger $\gamma$ or increasing the breaker delay effect $(F a c B k d=-2)$ limits the cross-shore migration (see Fig. 12). The contrary is not observed for a smaller value of $\gamma$ but occurs when the breaker delay is turned off. With the breaker delay turned off, with a smaller value of $\gamma$ or with a larger roller energy dissipation rate $\beta$, the welding of the bar horns extremities increases as it can be observed in Fig. 12. At the beginning of the simulation, more the wave breaking energy is dissipated offshore, more welding is observed. On the offshore side, the bar migrates in the offshore direction meanwhile on the shoreward side, the bar horns extremities migrates toward the beach. Using a large breaker delay or a large value of $\gamma$ limits the welding but results in larger $\alpha_{h}$ and smaller $\alpha_{v}$ values at the end of the simulation (see Fig. 12), meaning that more dissipation occurs in the morphodynamics. Decreasing the roller energy dissipation rate with small $\beta$ values similarly limits the welding and increases the alongshore cross-shore crest-trough distance $\alpha_{h}$ but it preserves the value of $\alpha_{v}$. Increasing $\gamma$ or FacBkd moves the breaking position shoreward and decreases the welding of the bar horns but it also brings 
more energy in smaller depth resulting in larger morphodynamic dissipation. Decreasing $\beta$ does not influence the wave breaking position and thus the cross-shore migration of the bar but it limits the welding by spreading the roller energy dissipation rather than translating it shoreward.
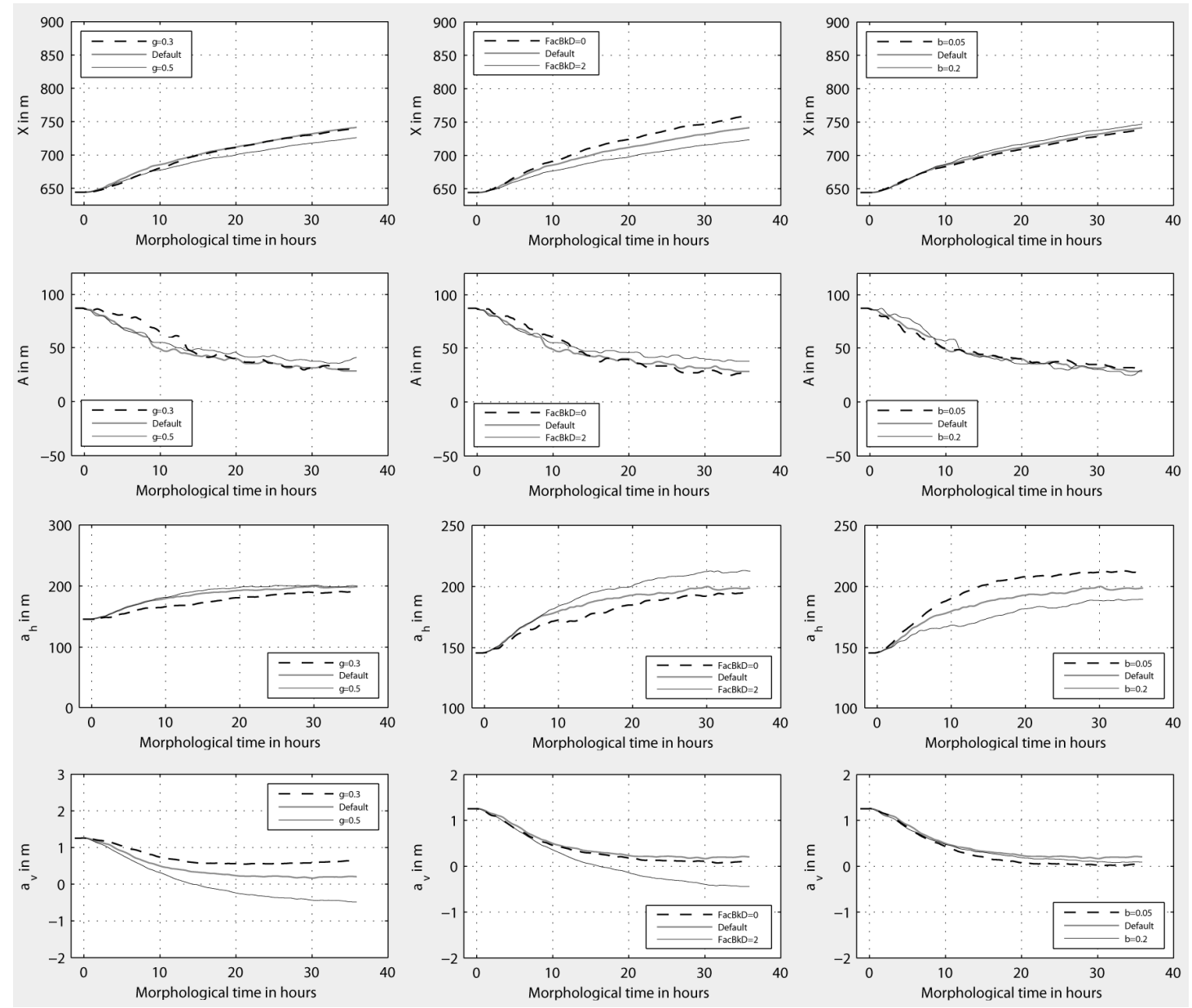

Figure 12. From the top to the bottom: Parameters $\mathrm{X}, \mathrm{A}, \alpha_{h}$ and $\alpha_{v}$ for three sensitivity analysis performed on $\gamma$ (left), FacBkd (center), and $\beta$ (right).

Other processes have finally been evaluated in the present study. The wave groups and therefore the occurrence of infragravity waves influence mainly the straightening of the bar. The absence of wave groups decreases the straightening rate of the bar but does not prevent it to occur.

The activation of the wave-current interaction in the model slows down the reset-event significantly in terms of migration as well as straightening by decreasing the intensity of the currents in the surfzone.

The use of a variable bed roughness linked to the generation of bed forms (Van Rijn, 2007) instead of a constant bed roughness in the computational domain of the flow did not impact the morphodynamics significantly as well as the activation of the sediment transport relative to the short waves asymmetry.

\section{DISCUSSION}

An analysis of the skewness of the velocities measured at Le Truc Vert during the decennial storm has been performed. It shows that the reset likely occurred at high tide when the sediment transport was directed offshore and southward. It also shows that the infragravity waves may have played a significant role in the sediment transport during the storm. However, their contribution becomes relevant once the longshore current has developed in the bar trough, thus probably once the reset occurred. This can be related to the fact that later in the simulations, the absence of wave groups did not influence significantly the reset-event. 
A numerical approach is used to characterize the processes that have induced the reset of the subtidal bar and thus to understand what processes are critical in a reset-event. A research version of Delft3D and Xbeach has been adapted to the specific case of Le Truc Vert. A calibration preformed with calm and energetic conditions resulted in a fair agreement of the simulated wave heights and mean currents with the observations.

First the hydrodynamics have been studied on the initial bathymetry without updating the morphology, using external conditions representative from the decennial storm conditions. The combination of pressure and wave-induced forces results in specific forcing patterns similar to a central force pattern at the bar horns. The consequence is the occurrence of specific circular flow patterns with strong onshore directed currents above the bar horns first turning towards the wave origin of propagation and then back towards the bar horns. On the other hand strong longshore currents are observed downward the wave direction of propagation southward of the bar horns.

The morphodynamic simulations are very sensitive to the description of the turbulence. Therefore constant flow viscosity and sediment diffusion coefficients have been used in the horizontal and vertical dimensions. In this case the sensitivity of the model to the flow viscosity and the sediment diffusion becomes reasonable. Using external conditions corresponding to the reset-event of ECORS, a reset of the subtidal bar is observed in the reference simulation. This reset agrees qualitatively with the observations given in Almar et al., 2010 describing the reset in terms of cross-shore migration and crescentic amplitude of the bar. The generation of a SPAW at the largest horn is even observed in the simulation as well as in the observations.

Incident energy intensity. The present study shows that an increase of the incident wave energy is not able to override the influence of the bathymetry on the currents. This is due to the fact that an increase of the significant wave height induces simultaneously an increase of the water level set-up and set-down as well as an increase of the wave dissipation. Thus, both the pressure and wave induced forces increase and the flow circulations are conserved. The morphodynamic simulations show that with the same energetic conditions, a reset can be observed (sufficient wave angle of incidence, sufficient water level) or not (normal wave incidence, low tide water level). The study of the hydrodynamics shows that the conditions preventing the occurrence of the reset corresponds to the conditions preserving or even amplifying the circular patterns in the flow time and depth-averaged velocity field. These characteristic flow patterns result in a conservation of the bar complex shapes and are thus responsible for the so-called self-organization behavior of nearshore sandbars. The fact that an increase of the wave energy is not sufficient to override the flow circulations induced by the bathymetry explains why energetic conditions do not systematically lead to the reset of nearshore sandbars as mentioned in Smit, 2010. However they are required as low energy cannot enable the evolution of the bar morphology as observed in the simulations.

Longshore current. The combination of the hydrodynamic and morphodynamic studies shows that the conditions leading to a reset of the subtidal bar corresponds to those inducing a significant longshore current in the surfzone. With an increase of the wave incidence or of the water level, a southward longshore current develops over the subtidal bar and in the trough between the bar and the shoreline. This results in a strong weakening of the circular flow patterns induced by the bathymetry and therefore in a forced behavior of the subtidal bar. In the model, the longshore current is necessary to switch the subtidal bar behavior from self-organized to forced. Fig. 13 illustrates the influence of the wave energy and the longshore current on the subtidal bar characteristics.

During storm 3, high wave heights occur with normal wave incidence. The bar migrates offshore but the crescents amplitude does not decrease. Immediately after, a significant longshore current appears but the wave energy is very low, thus the bar state is constant. During the initial part of the fourth storm (before day 86), high wave heights ( 3 to $4 \mathrm{~m}$ ) occur with a wave incidence between 20 and $40^{\circ}$. A strong longshore current coincide with a decreasing of the crescents amplitude meanwhile the bar migrates shoreward. In the second part of the storm, the wave height remains similar but the wave angle of incidence is much smaller (less than $10^{\circ}$ with the normal). A significant increasing of the crescents amplitude is observed. The data thus confirms the results of the simulations. The cross-shore migration and the straightening of the bar can be simultaneous or not. In addition, the data shows that high wave energy is required for the bar morphology to evolve and the energy level controls the bar cross-shore migration. On the other hand, the longshore current is necessary for the straightening of the bar. 


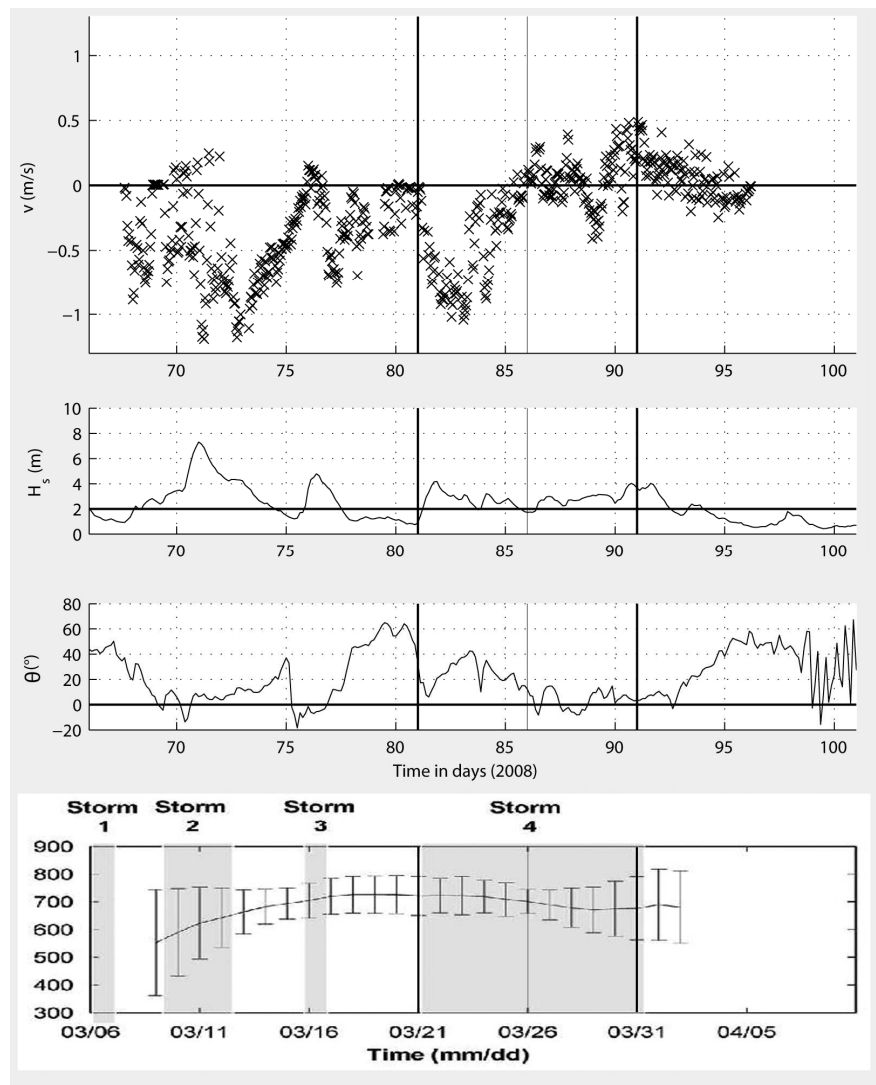

Figure 13. From top to bottom: one hour-averaged longshore velocities at the location of sensor number 2 , significant wave height, wave angle of incidence and subtidal bar $X$ and $A$ characteristics described in Almar et al., 2010 measured during the ECORS campaign. During the fourth storm, the bar straightening is linked to the occurrence of a longshore current in the surfzone and is not coinciding with an offshore bar migration.

Wave breaking and SPAWs. The horizontal hydrodynamics are not very sensitive to the parameters describing the wave breaking process. A slight translation of the flow patterns is observed in the cross-shore direction depending if the waves break more onshore or offshore. On the contrary, the morphology responds significantly. The subtidal bar migrates more or less offshore according to the wave breaking position. In addition, this position as well as the rate of dissipation of the wave breaking energy in the flow controls the generation of SPAWs as observed during ECORS. This suggests that the offshore migration of the bar and the onshore migration of the SPAWs are linked to the vertical structure of the hydrodynamics in the model but this has not been studied in the present work.

Other processes. Morphodynamic simulations have been performed to study other processes. The wave groups and infragravity waves have been found to have a very limited influence on the reset, their presence simply slightly accelerating the process. On the contrary, the interaction of the currents on the wave breaking considerably slows down the reset by decreasing the intensity of the currents in the surfzone. Introducing a variable bed roughness in the domain or ignore the sediment transport due the short waves asymmetry did not impact the reset significantly. The main processes involved in the reset are therefore the longshore current and the wave breaking strongly dependant on the wave energy intensity and incidence. The water level is important and the tidal variations induce a switch between the self-organized and the forced behaviors of the bar. However, the offshore bar migrations during the low tide periods decrease the influence of the morphology and enable then the reset to occur.

\section{CONCLUSION}

The processes involved in the reset of a subtidal bar have been characterized thanks to the analysis of field data and numerical modeling. The model has been able to reproduce the observations qualitatively. Indeed in the simulation as in the observations, the subtidal bar migrates offshore, the 
crescents amplitude decreases and the bar straightens. Moreover, shoreward propagating accretionary waves occur during the simulated and observed reset-event.

In the simulation, the complete reset results from the combination of high energetic conditions activating the subtidal bar migration and a significant longshore current inducing the straightening of the bar. The cross-shore migration of the bar and the generation of SPAWs are linked to the wave breaking process. The first is related to the wave breaking position and the latter depends on the wave breaking position and the wave breaking energy dissipation rate. In the model, the external conditions influencing the wave breaking are the incident wave energy intensity and the water level (therefore the tides). The external conditions relative to the longshore current intensity are the wave angle of incidence and the water level (therefore the tides as well).

The observations during ECORS confirm the role of the longshore current. The bar has been found to straighten and migrate onshore simultaneously at the beginning of the fourth storm experienced during ECORS. A strong longshore current was occurring then in the surfzone. At the end of this storm, the alongshore variability of the bar increased meanwhile the incident wave height did not vary. The waves were then almost normal to the shore and the longshore current was almost nonexistent. Thus in the reset process, the emergence of the longshore current appears to be the critical process enabling the bar behavior to switch from self-organization to a forced behavior. This is clear regarding the time and depth-averaged structure of the flow above the bar under energetic conditions. The self-organization results from characteristic circular patterns above the bar horns that tend to preserve the crescentic shape of the subtidal bar. The increasing of the longshore current in the surfzone weakens these structures especially in the bar trough and therefore induces the bar straightening.

Other processes have a minor role in the reset of the subtidal bar. The absence of wave groups in the model decreases the straightening rate of the bar but does not prevent it to occur. The activation of the wave-current interaction in the model decreases the intensity of the currents and therefore slows down the reset-event significantly. The use of a bed roughness depending on the flow velocities instead of a constant bed roughness in the computational flow domain did not impact the morphodynamics significantly as well as the inactivation of the sediment transport relative to the short waves asymmetry.

\section{ACKNOWLEDGMENT}

I would like to thank Nadia Sénéchal, Bruno Castelle and Ad Reniers for their participation in the ECORS campaign and their datasets. Regarding the numerical aspects, I am grateful to Dano Roelvink for his help in the improvement of the research model used in the present study. This research has been supported by Delft University of Technology and Deltares. This is the occasion to thank my supervisor Christophe Brière as well as Dirk-Jan Walstra and Maarten van Ormondt for their expert advice.

\section{REFERENCES}

Almar, R., B. Castelle, B. Ruessink, N. Sénéchal, P. Bonneton and V. Marieu, 2010. Two- and threedimensional double-sandbar system behavior under intense wave forcing and a meso-macro tidal range. Continental Shelf Research 30: $781-792$.

Castelle, B., P. Bonneton, H. Dupuis and N. Sénéchal, 2007. Double bar beach dynamics on the highenergy meso-macrotidal French Aquitanian Coast: A review. Marine Geology 245: 141 - 159.

Castelle, B., B. Ruessink, P. Bonneton, V. Marieu, N. Bruneau and T. Price, 2010a. Coupling mechanisms in double sandbar systems. Part 1: patterns and physical explanation. Earth Surface Processes and Landforms 35: 476-486.

,$- 2010 \mathrm{~b}$. Coupling mechanisms in double sandbar systems. Part 2: impact on alongshore variability of inner-bar rip channels. Earth Surface Processes and Landforms 35 (7): 771-781.

Deigaard, R., 1993. A note on the three-dimensional shear stress distribution in a surf zone. Coastal Engineering 20: 157 - 171 .

Droenen, N. and R. Deigaard, 2007. Quasi-three-dimensional modeling of the morphology of longshore bars. Coastal Engineering 54: 197 - 215.

Falqués, A., N. Dodd, R. Garnier, F. Ribas, L. MacHardy, P. Larroudé, D. Calvete and F. Sancho, 2008. Rhythmic surf zone bars and morphodynamic self-organization. Coastal Engineering 55: $622-641$. 
Garnier, R., D. Calvete, A. Falquès and N. Dodd, 2008. Modeling the formation and the long-term behavior of rip channel systems from the deformation of a longshore bar. Journal of Geophysical Research 113: C07053-.

Holman, R., S. G., E. Thornton and R. Ranasinghe, 2006. Rip spacing and persistence on an embayed beach. Journal of Geophysical Research 111.

Howa, H., 2003. Environnements littoraux silico-clastique, dominés par les houles - Bilan de recherche 1992/2002. Tech. rep., University of Angers.

Lippmann, T. and R. Holman, 1990. The Spatial and Temporal Variability of Sand Bar Morphology. Journal of Geophysical Research 95: 11575 - 11590.

Masselink, G., M. Austin, J. Tinker, T. O’Hare and P. Russell, 2008. Cross-shore sediment transport and morphological response on a macrotidal beach with intertidal bar morphology, Truc Vert, France. Marine Geology 251: 141 - 155.

Masselink, G. and A. Short, 1993. The Effect of Tide Range on Beach Morphodynamics and Morphology: A Conceptual Beach Model. Journal of Coastal Research 9: 785 - 800.

Reniers, A., J. Roelvink and E. Thornton, 2004. Morphodynamic modeling of an embayed beach under wave group forcing. Journal of Geophysical Research 109 (C1): C01030-.

Rijn, L. v., 2007. Unified view of sediment transport by currents and waves, part I, II, III and IV. Journal of Hydraulic Engineering, ASCE 133: Issue 6 and 7.

Roelvink, J., A. Reniers, A. v. Dongeren, J. v. Thiel de Vries, R. McCall and J. Lescinski, 2009. Modeling storm impacts on beaches, dunes and barrier islands. Coastal Engineering 56: 1133 1152.

Roelvink, J. and M. Stive, 1989. Bar-generating cross-shore flow mechanisms. Journal of Geophysical Research 94: 4785-4800.

Smit, M., 2010. Formation and evolution of nearshore sandbar patterns. Ph.D. thesis, Delft University of Technology.

Sénéchal, N. and F. Ardhuin, 2008. ECORS Truc Vert 2008: a Multi-Institutional International Nearshore Field Experiment. AGU Fall Meeting Abstracts pages B2+.

Stelling, G. and S. Duinmeijer, 2003. A staggered conservative scheme for every Froude number in rapidly varied shallow water flows. International Journal for Numerical Methods in Fluids 43: 1329-1354.

Wright, L. and A. Short, 1984. Morphodynamic variability of surf zones and beaches: A synthesis. Marine Geology 56: 93 - 118. 